

\title{
OS ESPAÇOS PÚBLICOS: DES ENCONTROS ENTRE OS MORADORES DA CIDADE (BAIRRO) E OS ESPAÇOS DE LAZER
}

\author{
Jeferson Rodrigo Vallau Pinheiro ${ }^{1}$ \\ Maria Simone Vione Schwengber ${ }^{2}$
}

\section{RESUMO}

O presente artigo traz um recorte da dissertação 'Plano diretor participativo do município de Ijuí/RS: gestão dos espaços públicos de lazer'. Neste recorte, o objetivo é analisar como os espaços públicos de lazer são tratados na política urbana do município de Ijuí/RS, a partir da amostra de um bairro contemplado pelo programa 'Minha Casa Minha Vida', com aporte de recursos públicos federais. A metodologia utilizada foi pesquisa qualitativa com base em estudos exploratórios, observações sistemáticas diárias em períodos diferentes, registros fotográficos e pesquisa documental. A análise indica que os espaços públicos de lazer se tornam pouco positivos e que as construções e revitalizações desses espaços não entram nas pautas de governo. Reconhecemos que hoje existe uma política habitacional no Brasil, embora ainda com tendência para construção, edificação, lotação, sendo deslocada ainda de uma política de espaços de lazer - o que denominamos como uma política marcada pelo des-encontro entre os moradores, a cidade (bairro) e os espaços de lazer.

Palavras-chave: Cidade. Espaço público. Lazer.

\begin{abstract}
This article provides an outline from the dissertation 'Participative master plan of the city of Ijuí/RS: management of public leisure spaces'. In this frame, the objective is to analyze how public leisure spaces are processed in the urban policy of the city of Ijuí/RS, from the sample of a neighborhood covered by the program 'Minha Casa Minha Vida', with the investment of federal public resources. The methodology used was the qualitative research based on exploratory studies, daily systematic observations at different periods, photographic records and documental research. The analysis indicates that public leisure spaces become slightly positive and that the construction and renovation of theses spaces do not enter governmental agendas. We recognize that today there is a housing policy in Brazil, although with a tendency for construction, building, stocking, and also

$1 \quad$ Integrante grupo Paidotribus da Unijuí.

2 Professora do Mestrado e do Doutorado em Educação nas Ciências da Universidade Regional do Noroeste do Estado do Rio Grande do Sul - Unijuí.
\end{abstract}


shifted from a policy of leisure spaces - what we call a policy marked by meeting/division between residents, the city (neighborhood) and leisure spaces.

Keywords: City. Public space. Leisure.

\section{RESUMEN}

El presente artículo presenta apartes de la disertación "Plano director participativo del municipio de Ijui/RS". En dichos apartes, el objetivo es analizar cómo los espacios públicos de ocio son tratados en la política urbana del municipio de Ijui/RS, a partir de la muestra de un barrio contemplado por el programa "Mi casa, Mi vida", con el aporte de recursos públicos nacionales. La metodología utilizada fue una investigación cualitativa con base en estudios exploratorios, observaciones sistemáticas diarias en periodos diferentes, registros fotográficos e investigación documental. El análisis indica que los espacios públicos de ócio se tornan poco positivos y que las construcciones y revitalizaciones de esos espacios no entran en las pautas del gobierno. Reconocemos que hoy existe una política habitacional en Brasil, aunque aún con tendencia para construcción, edificación, abarrotación, siendo desplazada para una política de espacios de ócio - que denominamos con una política marcada por el des-encuentro entre los habitantes, la ciudad (barrio) y los espacios de ócio.

Palabras-clave: Ciudad. Espacio Público. Ocio.

\section{INTRODUÇÃO}

Nas cidades contemporâneas, existe a sensação de um crescimento 'material' demasiado e de maneira desorganizada, produzindo uma nova remodelação no espaço geográfico, em ruas, muros, prédios, indústrias, carros, e outros diversos tipos de elementos que mudam as paisagens do ambiente urbano. O problema é que esse crescimento se deu (e se dá) muitas vezes de forma descontrolada, e a falta de planejamento cobra seu preço, trazendo impactos negativos sobre o acesso a bens e serviços, à infraestrutura, à qualidade de vida e ao exercício da cidadania. Refletir sobre o espaço nas cidades abre diversos caminhos metodológicos de investigação. Escolhemos discutir neste artigo uma relação entre lazer e espaço público urbano, perguntando: A cidade possibilita e/ ou impede a fruição ao oferecer espaços para lazer? Os espaços de lazer se identificam como uma dimensão pública da cidade?

Desde que o humano diminuiu o cuidado doméstico para se aventurar e trabalhar na vida da cidade, a vida pública tornou-se tão importante ou mais do que a vida privada. "No mundo moderno, as duas esferas constantemente recaem uma sobre a outra, como ondas no perene fluir do próprio processo da vida" (ARENDT, 1989, p. 42). A vida pública na cidade se constitui não só pela convivência de pessoas diferentes, como também por sua participação em um contrato social que tem caráter público; contrato tácito baseado e estruturado inicialmente pelo e no espaço público, que constitui de forma permanente o contrato. Aproximamo-nos de uma posição que aposta na dimensão pública e na dimensão política de um contrato social da potência da dimensão coletiva e do uso multifuncional do espaço público, da rua, do lugar do encontro, inclusivo, de lazer. 
As cidades no contexto de mudanças, sobretudo econômicas, nos permitem observar, no caso específico do Brasil, uma crescente verticalidade da globalização. O espaço geográfico da cidade, usado para fins econômicos, dada uma jornada de trabalho mundial estipulada de cinco dias na semana, oito horas por dia, coloca o espaço como a esfera das negociações, criado pelas relações de mercado. Segundo Massey (2009, p. 150), "[...] é um espaço, também que está para sempre incompleto e em produção".

Como poderemos (re)pensar um espaço público de representatividade que possa acolher espaços de lazer que potencializem o encontro e as vivências num mesmo local, diminuindo as diferenças e igualando as possibilidades reais da convivência entre os diferentes? Não há como negar que o espaço público de lazer é genuinamente o espaço geográfico da multiplicidade; sendo assim, esse lugar também poderá trazer multiplicidade de ideias, imaginações, compreensões, significados, de relações. Defendemos a urgente necessidade de discutir uma política de investimento na retomada da qualidade dos espaços de lazer da cidade; propomos uma posição mais democrática de utilização do espaço público, da vida pública, porque entendemos ser também mais sustentável.

Tomemos, então, o caso de uma cidade do Brasil, localizada na região noroeste do estado do Rio Grande do Sul, chamada de Ijuí, para empiricamente discutir o espaço público de lazer. Na próxima seção, discutimos o conceito de lazer, pensando-o como encarnado à cidade.

\section{DEFINIÇÕES DE LAZER}

Os estudos sobre lazer, embora estejam aumentando em número, considerando as publicações contemporâneas, não permitem dizer que as suas definições estão fechadas, concluídas, e é por este motivo que conceituar lazer não é uma tarefa fácil. Trouxemos algumas definições de Dumazedier (1980, 1999, 1995, 2002), Gomes (2004, 2008, 2009), Marcellino (1996, 2000, 2001, 2002), De Masi (2000) e Mascarenhas (2004) que se mostram importantes para esta análise.

Em grande parte da literatura, as discussões e as compreensões de lazer relacionam-se intimamente com o mundo laboral, especialmente a partir de uma visão construída com as lutas dos trabalhadores pela redução das horas de trabalho e pelo aumento das horas de descanso e/ou de lazer. Períodos maiores de tempo livre para quem trabalha, sobretudo horas a mais fora da jornada de trabalho, significaram uma conquista considerável para os trabalhadores. Desse modo, as primeiras questões teóricas sobre o lazer discutiam a importância, mais subjetiva, das atividades de lazer para os sujeitos trabalhadores.

Para Dumazedier (1980, p. 19), lazer é

[...] um conjunto de ocupações às quais o indivíduo pode entregar-se de livre vontade, seja para repousar, seja divertir-se, recrear-se, ou ainda para desenvolver sua informação ou formação desinteressada, sua participação social voluntária ou sua livre capacidade criadora após livrar-se ou desembaraçar-se das obrigações profissionais, familiares e sociais.

Dumazedier foi um dos pioneiros a aprofundar-se no campo teórico dos estudos sobre o lazer e influenciou os pesquisadores brasileiros. O autor $(1995,2002)$ destaca o lazer como sendo as 
atividades em áreas de interesse diferenciadas que compõem um todo interligado. Ele classifica as atividades de lazer em categorias quanto ao conteúdo: do universo estético feito de imagens, de emoções, de sentimentos (como cinema, televisão, igreja); do universo intelectual: cognição, informação (exemplo: busca de conhecimentos, jornais, revistas, acesso à literatura); do universo físico: desenvolvido através de práticas corporais e esportivas, (exemplo: caminhadas, ginástica, esporte e atividades correlatas, executadas de maneira formal ou informal, em espaços tecnicamente planejados, como pistas, academias, clubes, escolas esportivas); do universo social: espaços como os das festas noturnas, boates, pubs, discotecas; do universo turístico: desenvolvido através de atividades turísticas (viagens, passeios).

Gomes $(2009$, p. 62)) defende a ideia de que Dumazedier "procurou explorar as implicações do que considerou como lazer sem, no entanto, compreender a dinâmica social que permite a sua manifestação em nossa sociedade". O fenômeno do lazer está ligado aos processos espaciais, uma vez que cada construção cultural depende do contexto social onde se realiza, do cotidiano onde os sujeitos criam as técnicas corporais próprias de sua cultura e de seus modos específicos de lidar com os limites de tempo, lugar, infraestrutura, condições econômicas e outras dimensões que condicionam suas realizações no lazer.

Gomes (2004, p. 29) entende que o "lazer é uma dimensão da cultura caracterizada pela vivência lúdica de manifestações culturais (tais como as festas, os jogos, as brincadeiras, os esportes, as artes e até mesmo o ócio) no tempo/espaço conquistado pelos sujeitos e grupos sociais". O que destacamos dessas observações, e que se torna pertinente a esta discussão, é o tempo e o espaço do lazer.

Para Harvey (1994, p. 189), "podemos afirmar que as concepções do tempo e do espaço são criadas necessariamente através de práticas e processos materiais que servem à reprodução da vida social". São esses processos que nos permitem entender o espaço e o tempo. É por isso que o lugar de onde falamos é importante para a compreensão do tempo e dos espaços de lazer. Segundo Callai (2000, p. 84), "as regras podem ser gerais, os interesses universais, mas concretamente se materializam em um lugar específico. É o nível do local que traz em si o global, assim como o regional e o nacional".

O espaço de lazer tem ligação também com a educação das massas. Mascarenhas (2004, p. 17), ao descrever essa ligação do lazer com a educação, explica que "o lazer se apresenta como lugar de uma experimentação valorativa em que a estética, a ética e a política articulam-se como dimensões que acabam por tornar impossível qualquer iniciativa de dissociá-lo da educação". Em seu livro Lazer como prática da liberdade, o autor descreve o lazer no campo da educação, defendendo a ideia de que o lazer deve ser entendido como tempo e espaço de construção da cidadania e do exercício da liberdade. E assim, para Mascarenhas (2004, p. 13), "o lazer é como força de reorganização da sociedade, uma agência educativa, capaz de fomentar e colaborar para a construção de normas, valores e condutas para o convívio entre os homens".

Marcellino (2002) diz que se deve levar em conta que, se o conteúdo das atividades de lazer pode ser altamente "educativo", também a forma e o lugar onde são desenvolvidas abrem possibilidades "educativas", uma vez que o componente lúdico do jogo, do brinquedo, do "faz-de-conta" que permeia o lazer é uma espécie de denúncia da "realidade", deixando clara a contradição entre obrigação e lazer. Por meio das práticas culturais do jogo, por exemplo, as pessoas estabelecem relações com o universo do lazer, pois as características dessas práticas são as forjadas no local, podendo ser 
também nacionais ou globais. "Sua trama cultural evidencia que é tempo/espaço de manifestação do tradicional e da novidade, de conformismo e de resistência" (GOMES, 2008, p. 6).

O lazer é uma criação humana que está em constante diálogo com as demais esferas da vida. E, segundo Gomes $(2009$, p. 63), "participa da complexa trama histórico-social, que caracteriza a vida em sociedade, e é um dos fios tecidos na rede humana de significados, símbolos e significações". Os conceitos de lazer perpassam diferentes contextos e práticas sociais, e por isso os olhares sobre o lazer são diferentes e complementares. Cada pesquisador pode adotar um ponto de vista distinto para compreender o lazer (GOMES, 2009).

Postos aqui os conceitos da definição de lazer para o momento, passamos a discutir a relação entre lazer e as condições espaciais que se encontram nos espaços destinados às suas práticas na cidade.

\section{ESPAÇOS DE LAZER}

O espaço, para nós humanos, inclui os de lazer. Os espaços podem ser políticos, sociais ou culturais, mas nunca neutros, pois há neles sempre uma relação de poder. O espaço onde o lazer é desenvolvido pode potencializar diversas práticas de atividades, principalmente pode favorecer as relações sociais e os processos educativos que ali são vividos. Para Bramante (1998), o lazer se traduz por uma dimensão privilegiada da expressão humana dentro de um espaço e de um tempo conquistado. Trata-se de criarmos espaços de lazer. O lazer é uma dimensão preciosa do viver humano, através do qual o homem e a mulher produzem seus meios de vida, suas relações com os outros e consigo mesmos, com a sociedade e com a cidade na qual vivem.

O lazer é estudado aqui não apenas como tempo, mas fundamentalmente como espaço, ou seja, o espaço como meio de desenvolvimento das práticas de lazer. $\mathrm{O}$ tempo pensado pela produção econômica (globalização) é o "tempo cronológico", do grego chronos, ou o tempo enquanto horas, dias, meses; o tempo que nós relacionamos com o espaço de lazer é o "tempo vivido" ou o tempo do humano, um tempo em que o sujeito está livre de suas obrigações, sejam elas de qualquer ordem; tempo em que a intencionalidade produtiva das práticas não está presente - a única intencionalidade é divertir-se e aproveitar um momento de relações com o espaço e com atividades de puro lazer.

Conquistamos a velocidade, a diminuição virtual da distância, mas também a limitação de uso dessas virtualidades, já que nem todos conseguem pagar por elas. Para Santos (2000, p. 33), "novos significados são atribuídos ao tempo, um tempo milimetrado que foge do homem, e, também, um tempo da impermanência, que acarreta o empobrecimento psicológico e emocional". É dessa reflexão que parte a preocupação também com os espaços físicos de lazer, que não sejam os hegemônicos (colocados à venda pelo mercado do lazer). De Grazia (apud PIMENTEL, 1962) afirma que o lazer não pode ser pensado apenas em termos de tempo, esclarecendo que o "tempo disponível" não é suficiente para a existência do lazer. Este autor critica a expressão que faz referência ao "tempo de lazer", pois acredita que este termo esteja equivocado, uma vez que, não havendo espaços de lazer atrativos para uma prática adequada, ou um estímulo que pode ser de ordem subjetiva, de nada adiantaria possuir o "tempo de lazer". É relevante entender que as atividades de lazer não estão relacionadas apenas com o tempo, mas também com os espaços vividos. 
O lazer, como meio de expressão humana de cultura, ludicidade e da livre escolha, deve ser potencializado com espaços públicos para favorecer a fruição de práticas escolhidas. Santos (1997, p. 100) afirma "que o espaço se redefine como um conjunto indissociável no qual os sistemas de objetos são cada vez mais artificiais e os sistemas de ações são, cada vez mais, tendentes a fins estranhos ao lugar". O autor chama atenção para a mudança nos espaços em função da produção econômica. Nós nos apropriamos dessa reflexão para trazer essa discussão para o espaço público de lazer, falando da qualidade dos espaços públicos da cidade. Há uma intencionalidade que se tenta dar às funcionalidades dos objetos públicos de lazer, construída aparentemente desde o momento de sua concepção até o momento de sua criação e produção (SANTOS, 1997).

Da cidade e do espaço público urbano esperamos que favoreçam os encontros do inesperado, da amizade e do confronto. O espaço público de lazer é inevitável e simultaneamente de concordância e de conflito, porém é nessa base que se estabelece a (re)produção do espaço urbano pela sociedade. Santos (1997) discute alguns argumentos que nos levam a crer que a remodelação espacial pensada pelos agentes hegemônicos se constrói a partir de uma vontade distante e, na grande maioria das vezes, estranha, mas que se impõe à consciência dos que praticam essa vontade.

Dumazedier (1999) aponta que existe uma necessidade de organização dos lazeres. Como Santos (2000, p. 36) afirma, "trata-se, no fundo, de uma questão de civilização. O problema não é, apenas, proteger recursos e lugares, mas valorizar o humano", nos espaços públicos da cidade.

Entender o espaço urbano e também o espaço público de lazer é buscar a compreensão das complexas mudanças ocorridas nas organizações das cidades. Quanto mais complexo é o aumento material das cidades, maiores são a complexidade e a diversificação dos objetos e das ações (SANTOS, 1997). As redefinições nas estruturas das cidades implicam diretamente a organização do espaço, redefinindo-o em todos os seus níveis de organização.

Hoje, uma organização precede e preside à estruturação (da cidade) [...]. A partir do nível mundial, ditando as formas de vida das sociedades as mais diversas, e pretendendo mesmo impor as modalidades com as quais os diversos povos realizam o seu estatuto nacional [...]. Este ditame organizacional externo a cada nação, e que impõe, dentro de cada país, novas formas de convivência, termina por redefinir, redimensionar e reorganizar tudo, até mesmo o espaço. (SANTOS, 1997, p. 100).

Para que de fato o lazer possa fazer parte da cultura, é importante que existam espaços para as pessoas usufruírem. Podem ser os espaços da residência, de ruas, praças, parques, até mesmo dos bares das cidades. O que importa é que tenhamos em nossa vida na cidade uma relação mais estreita com os espaços públicos e as práticas de lazer, que não podem vir prontas com os espaços, mas que sejam construídas por nós.

O espaço de lazer construído possui elementos materiais para favorecer as práticas que se pensam para a população. Embora o espaço público de lazer dê certa direção para a escolha das atividades, as pessoas o recriam conforme sua representação do lugar/território.

A cidade, por sua natureza, é um espaço conflitivo. Sua produção é social, mas sua apropriação é seletiva. Assim, os espaços têm valor de troca de capital, afastando de áreas ricas em espaços de lazer pessoas que não se sentem pertencentes a determinados lugares, o que pode ser explicado 
pelas diferenças de classes econômicas. Há espaços pela cidade que são ressignificados pelas políticas públicas, favorecendo o surgimento de novas formas para sua utilização, antes marcadamente populares, mas que se modificaram com as práticas estabelecidas pela classe média, como o cooper praticado nas manhãs e fins de tarde. O comércio é impulsionado por vários supermercados e bares, os quais oferecem uma gama de produtos, e o próprio consumo da paisagem, com a construção de 'ilustres' casas e novos empreendimentos comerciais e imobiliários.

Pela cidade se espalham áreas ricas e pobres. Como identificar a riqueza de uma e a pobreza de outra? Olhando para as áreas da cidade, percebemos quais são as áreas ricas e quais as pobres, baseados no fato de que a cidade está dividida assim. A apropriação territorial da cidade é realizada através da comercialização de modo a favorecer a divisão de classes. Segundo Santos (2010, p. 99), "o dinheiro é, cada vez mais, um dado essencial para o uso do território". Essa divisão impõe ao cidadão a procura de espaços, o lugar que seu capital financeiro pode alcançar. No entanto, quando a cidade cresce em áreas construídas, a saída é procurar áreas periféricas que deixam de ser 'áreas dos desfavorecidos' para serem ocupadas por pessoas que não encontram outras mais nobres, próximas dos centros comerciais das cidades.

Em primeiro lugar, para que se tenham espaços públicos de qualidade, em especial de lazer, é necessário que se faça entender pela população a importância destes em nossas vidas. É inegável também que a culpa por esse estado de desconhecimento sobre os deveres da população (tratandose da participação na elaboração de projetos para o lazer municipal) cabe aos legisladores, que não criaram (criam) as condições de treinamento das pessoas para o uso adequado do lazer e, principalmente, do espaço e do tempo livre.

Na próxima seção, abordaremos a cidade de Ijuí/RS, levantando algumas características para situar os leitores no lugar sobre o qual estamos tratando.

\section{O MUNICÍPIO DE IJUÍ/RS}

Para que entendamos de qual lugar geográfico estamos falando, descrever a cidade de Ijuí/RS se faz necessário. Ijuí é um município brasileiro com uma população total de aproximadamente 79. $396^{3}$ habitantes, dos quais 71.555 moram na área urbana. Possui $689,133 \mathrm{~km}^{2}$ de território, com uma taxa populacional urbana de 90,66\%, e rural de 9,33\%. Município de expressão em âmbito regional e estadual, destaca-se como cidade prestadora de serviços para mais de 48 municípios da região4.

Conhecida como Terra das Culturas Diversificadas, a intenção de integrar imigrantes de várias etnias para não causar conflitos na constituição do município foi levada ao extremo por Ijuí. Dos variados grupos étnicos, citamos os seguintes: afro-brasileiros, portugueses, franceses, italianos, alemães, poloneses, austríacos, letos, holandeses, suecos, espanhóis, árabes, libaneses, lituanos, ucranianos, dentre outros. Uma babel de línguas e culturas 'no meio do mato', em uma região rural do Brasil.

3 Fonte: IBGE, Diretório de Pesquisas - DPE. Coordenação de População e Indicadores Sociais.

4 A cidade localiza-se no noroeste do estado do Rio Grande do Sul, em um entroncamento rodoviário que é passagem obrigatória para o Mercosul, e a $441 \mathrm{~km}$ da capital Porto Alegre. 
Ijuí é uma cidade universitária que recebe diariamente alunos da cidade e de outros municípios da região. As potencialidades ${ }^{5}$ de Ijuí são expressas através de uma economia baseada no setor agropecuário, na prestação de serviços, destacando-se o ensino conferido pela Universidade Regional do Noroeste do Estado do Rio Grande do Sul (Unijuí) e também os serviços de atenção à saúde, como as especializações oferecidas pelo Hospital de Caridade de Ijuí (HCI).

Conforme a Secretaria de Planejamento e Coordenação (Seplan, 2007), a taxa de analfabetismo em Ijuí corresponde a 4,78\%. A expectativa de vida ao nascer (dados de 2000) é de 69,14 anos 6 . Sobre o coeficiente de mortalidade infantil de 2010, a cada mil crianças nascidas vivas, 12,26 não sobreviveram. Em 2010, o PIB era de R\$1.817.366, e o PIB per capita, R\$26.028. O município de Ijuí possui 36 bairros.

\section{A remodelação política dos lugares na cidade}

Na primeira década do século XXI no Brasil há um movimento de ampliação de projetos públicos e políticos para melhorar a qualidade da moradia dos brasileiros, podemos ver uma aplicação maciça em casas próprias financiadas pelo governo para a população, através do projeto denominado Minha Casa Minha Vida. Este programa do Governo Federal tem transformado o 'sonho da casa própria', sendo direcionado para a população com renda mensal de até 10 salários mínimos. O programa funciona em parceria com estados, municípios, empresas e entidades sem fins lucrativos. Dos 36 bairros de Ijuí, cinco foram contemplados pelo programa, com a construção de 692 apartamentos.

O recorte feito neste artigo é para mostrar parte do impacto das novas edificações implantadas na cidade e os espaços públicos para o lazer urbano, tomando como base um bairro da cidade de Ijuí-RS, denominado Tancredo Neves. Situado ao norte da cidade, neste bairro não existe área de lazer construída pelo poder público para seus moradores.

Como é possível observa na imagem acima a construção do condomío nesse bairro agravou a situação (para as áreas de lazer). No ano de 2012, foi construído neste bairro ${ }^{7}$ um conjunto habitacional, que já contava com 1.505 moradores. Entendemos que o modo como se dá seu crescimento é um importante fator a ser localizado para o entendimento dos problemas sociais e estruturais encontrados ali, bem como a relação que essa comunidade tem com os espaços de lazer e de convívio social. Entendemos também que a urbanização (ou melhor, o crescimento da construção civil de uma cidade) é um dos elementos-chave para compreender o lazer. Este tem ampla articulação com crescimento residencial das cidades, uma vez que absorve elementos da cultura, das artes, das relações e do convívio social.

$5 \quad$ Fonte: $<$ http://www.unijui.edu.br/institucional/sobre-a-unijui $>$.

6 Fonte: FEE/Núcleo de Indicadores Sociais e IBGE.

7 Este é um dos motivos que nos levou a escolher o bairro Tancredo Neves como objeto de pesquisa. 


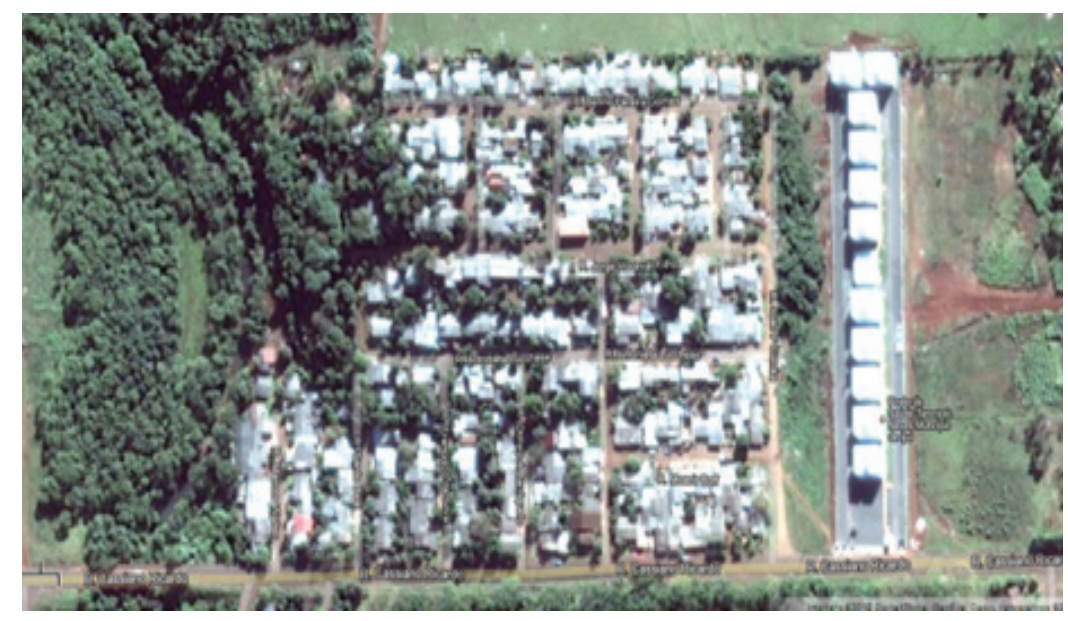

Figura 1 - Imagem por satélite do bairro Tancredo Neves (dezembro 2012)

O conjunto habitacional Júlio Taube, construído no bairro estudado, conta com nove blocos, cada um com quatro andares, divididos em quatro apartamentos por andar, abrigando 176 famílias no total. O terreno em que está alocado o condomínio foi escolhido dentro de uma área de terra mais desvalorizada na cidade.

Com esse condomínio, o bairro cresceu em número de pessoas e também em habitações. Como se pode observar na imagem, não há espaço para que as relações sociais, que não são estáticas e sim dinâmicas, aconteçam em sua plenitude, pois essas relações implicam o inesperado, geram uma nova rede de relações sociais entre os moradores do condomínio e os moradores do bairro Tancredo Neves.

O condomínio Júlio Taube se estabeleceu pelo poder público sem prévia preparação social dos entornos. Um dos elementos que chama-nos a atenção é justamente a falta de espaços para lazer e/ ou área coletiva de convivência, necessidade que se acentua de forma geral, já que o apartamento em si é relativamente pequeno. Conforme afirma Santos (1993, p. 46), são apartamentos "tão pequenos que conduzem a toda espécie de confinamentos [...]".

Entendemos que deveriam recair as leis do Plano Diretor Participativo sobre esse tipo de condomínio, na direção de garantir espaços que qualificariam as condições necessárias para as práticas de lazer. Espaços de lazer infelizmente não são encontrados nem no bairro, nem no condomínio. As práticas de lazer que poderiam beneficiar as relações sociais através de espaços qualificados parecem ser aqui ocultadas, nessa construção. Como é possível o convívio entre os moradores prévios do bairro e os 'novos' moradores que habitam o condomínio? Segundo Rolnik (2000, p. 182),

[...] a cidade se produz quando o homem, além da sua vida privada, de sua existência enquanto ser natural ou parte da natureza cria uma espécie de segunda vida, uma espécie de bios político ou ser político que se concretiza vivendo em conjunto com outras pessoas. A vida na cidade constitui-se não só pela convivência de pessoas diferentes, como também por sua participação de um contrato social que tem caráter público; contrato tácito baseado na palavra e na persuasão, na não violência e na não força. 
O espaço de lazer público neste condomínio poderia minimamente garantir e facilitar o encontro entre os des-conhecidos, entre os moradores novos com os já existentes no bairro. Mesmo que existissem espaços de lazer, seria conveniente o poder público municipal, por meio da Coordenadoria Especial de Lazer ${ }^{8}$, realizar algumas atividades que fomentassem a participação da comunidade.

Sabemos da importância do assistencialismo aos menos favorecidos, mas também que sejamos críticos a ponto de descrever a importância dos espaços públicos urbanos de lazer na estruturação social da vida humana. Uma regeneração urbana e o aproveitamento das oportunidades econômicas neste momento do país somente vêm a favorecer a criação de espaços significativos para o lazer público, recuperando os espaços dinamizadores, relacionando-os com um novo modelo urbano.

\section{LONGE DE CONCLUIR}

A intervenção urbanística brasileira é orientada estrategicamente por investimentos em grandes projetos somente para moradias. De modo geral, o lazer é apontado como uma necessidade a ser conquistada, apesar de configurar-se, desde 1988, como um dos direitos sociais assegurados no artigo $6^{\circ}$ da Constituição da República Federativa do Brasil, ao lado de saúde, educação e outros.

Embora o lazer seja essencial para a vida humana, ainda não ganha destaque pela cidade em espaços públicos. Mesmo reconhecido como um direito social, não tem indicação de que seja compreendido de forma mais ampla, como dimensão da cultura. Para que o lazer possa ser entendido como prática cultural, fazem-se necessárias ações que entendam a infraestrutura da cidade como eixo articulador, a 'coluna vertebral' na regeneração urbana para o lazer no espaço público.

As novas remodelações urbanísticas no Brasil poderiam atuar como elemento impulsionador, catalisador da dinâmica inclusiva e cultural do espaço público da cidade, e criar, por sua vez, as condições materiais e também sociais para o desenvolvimento de operações urbanas condizentes com a realidade que se apresenta para a cidade no momento.

Dessa forma, somente o espaço da casa não é suficiente para suprir a necessidade humana do lazer. Ademais, grandes infraestruturas e projetos devem ser parte de uma conscienciosa promoção da cultura, e não para fazer parte apenas de uma campanha de promoção de marketing urbano, dirigida para construir a imagem da cidade com arquiteturas emblemáticas.

Parafraseando Gomes (2009), o lazer como dimensão da cultura deve considerar o tempo/espaço disponível e a atitude assumida pelas pessoas nessas experiências, que são marcadas por um sentimento de liberdade (mesmo que seja apenas imaginada), impulsionada pela busca de satisfação e pelo desfrute do momento vivido. Isso indica que o lazer precisa de mais abertura no plano de uma cidade sustentável.

Em uma cidade como Ijuí, são necessárias conferências públicas municipais que venham a tratar de políticas urbanas, em especial de lazer. Não se trata aqui de inspecionar o que o trabalhador faz com seu tempo livre, mas sim de avaliar quais condições de lazer são oferecidas pelos administradores municipais que possam ter efeitos no campo do lazer na cidade. As ações administrativas precisam conceber o lazer como um importante meio de desenvolvimento cultural na cidade.

8 Responsável pelas organizações públicas de atividades de esporte e lazer. 
A esse respeito, os apontamentos encontrados neste artigo vêm ao encontro da pesquisa realizada por Silva et al. (2011). Eles constatam também que o lazer é uma importante dimensão da cultura e há muito está presente na Declaração Universal de Direitos do Homem e da Mulher. E que não foi de maneira simples que esses direitos foram conquistados pelos brasileiros, e estão descritos na Constituição Federal de 1988.

Urgem discussões entre administradores/gestores municipais ou regionais e a comunidade em geral na perspectiva de pensarmos a cidade que somos em favor da cidade que queremos ser. Essas questões só fariam enriquecer o planejamento urbano.

As áreas reservadas ao lazer ainda não está em um lugar de destaque em grande parte da vida das cidades brasileiras. Consideramos, para que isso venha acontecer, que tenhamos mais espaços para as vozes dos que vivem a cidade. Um planejamento estratégico, com uma gestão estratégica, pode fazer a diferença em favor da qualidade dos espaços da cidade. Considerar a visão de projetos populacionais orientadores no desenvolvimento urbano, estabelecendo uma relação dialética com as reais prioridades da cidade, rompendo com as hierarquias tradicionais nas tomadas de decisões.

Finalizando este artigo, desejamos dizer que o espaço, lazer e cidade precisa ainda de estudos mais alargados, ampliando os entendimentos acerca do tema, favorecendo uma maior garantia de direitos na política do planejamento urbano. Nosso investimento analítico neste artigo não se propõe como conclusivo e explicativo, longe de concluir. Ele busca, sim, uma contribuição ao debate a abertura as significações dos espaços de lazer nas cidades em tempos de ampliação de projetos de condominios contemporâneas.

\section{REFERÊNCIAS}

Arendt, Hannah. A Condição Humana. Rio De Janeiro: Forense Universitária, 1989.

Bramante, Antonio Carlos. Dos Clássicos Aos Contemporâneos: Revendo E Conhecendo Importantes Categorias Referentes Às Teorias Do Lazer. In: Pimentel, Giuliano Gomes De Assis; Marinho, Alcyane (Orgs.). Teorias Do Lazer. Maringá: Eduem, 2010. P.14-55

Brasil. Constituição Da República Federativa Do Brasil, De 5 De Outubro De 1988. Brasília: Congresso Nacional, 1988.

Callai, Helena Copetti. Estudar O Lugar Para Compreender O Mundo. In: Castrogiovanni, Antonio Carlos (Org.). Ensino De Geografia: Práticas E Textualizações No Cotidiano. Porto Alegre: Mediação, 2000.

De Masi, Domenico. Perspectivas Para O Trabalho E O Tempo Livre. In: Garcia, Erivelto B.; Lobo, Francis (Orgs.). Lazer Numa Sociedade Globalizada. São Paulo: Sesc/Wlra, 2000. P. 121137.

Dumazedier, Joffre. Planejamento De Lazer No Brasil: A Teoria Sociológica Da Decisão. Tradução De Regina Maria Vieira. São Paulo: Sesc-Codes, 1980. 
. Sociologia Empírica Do Lazer. São Paulo: Perspectiva: Sesc, 1999. (Debates, 164).

Gomes, Christianne Luce. Lazer - Concepções. In: (Org.). Dicionário Crítico Do Lazer. Belo Horizonte: Autêntica Editora, 2004.

Et Al. (Orgs.). Lazer Na América Latina / Tiempo Libre, Ocio Y Recreación En Latinoamérica. Belo Horizonte: Editora Ufmg, 2009.

Harvey, David. Condição Pós-Moderna. São Paulo: Loyola, 1994.

Marcellino, Nelson Carvalho (Org.). Políticas Públicas Setoriais De Lazer: O Papel Das Prefeituras. Campinas: Autores Associados, 1996.

. Estudos Do Lazer: Uma Introdução. São Paulo: Autores Associados, 2002.

Mascarenhas, Fernando. Lazer Como Prática Da Liberdade: Uma Proposta Educativa Para A Juventude. Goiânia: Editora Ufg, 2004.

Massey, Doreen. Pelo Espaço: Uma Nova Política Da Espacialidade. Rio De Janeiro: Bertrand Brasil, 2009.

Prefeitura De Ijuí. Executivo Entrega As Chaves De Apartamentos Na Pedreira. 26 Ago. 2013. Disponível Em: <Http://Www.ijui.rs.gov.br/Noticia/Index/21783>. Acesso Em: 21 Out. 2013.

Rolnik, Raquel. O Lazer Humaniza O Espaço Urbano. In: Garcia, Erivelto B.; Lobo, Francis (Orgs.). Lazer Numa Sociedade Globalizada. São Paulo: Sesc/Wlra, 2000. Santos, Milton. O Espaço Do Cidadão. São Paulo. Nobel, 1993.

. Técnica, Espaço, Tempo: Globalização E Meio Técnico-Científico Informacional. São Paulo: Hucitec, 1997.

. Lazer População E Geração De Empregos. . In: Garcia, Erivelto B.; Lobo, Francis (Orgs.). Lazer Numa Sociedade Globalizada. São Paulo: Sesc/Wlra, 2000.

Silva, Débora Alice Machado Da, Et A1. Importância Da Recreação E Do Lazer. Brasília: Gráfica E Editora Ideal, 2011. 